\title{
CUSTOS E RENDIMENTOS OPERACIONAIS DE UM PLANTIO DE EUCALIPTO EM REGIÃO DE CERRADO ${ }^{1}$
}

\author{
Kátia Regina Silva ${ }^{2}$, Luciano J. Minetti², Nilton César Fiedler ${ }^{3}$, Fábio Venturoli ${ }^{4}$, Edgar Gaya Banks \\ Machado $^{5}$, Amaury Paulo de Souza ${ }^{2}$
}

\begin{abstract}
RESUMO - A presente pesquisa foi realizada em uma área de implantação de um povoamento florestal de eucalipto da Fazenda Água Limpa, da Universidade de Brasília, com o objetivo de avaliar os custos de produção e os tempos gastos nas etapas de produção de mudas, preparo do solo, plantio e tratos culturais. Todos os custos de produção das diversas etapas foram analisados, sendo os tempos cronometrados com o uso do método de tempos individuais. De acordo com os resultados, o custo médio para a implantação de 1 ha de eucalipto foi de R \$ 703,02. Os maiores custos foram os da aquisição das bandejas e tubetes (28,3\%), combate a formigas $(16,7 \%)$, preparo do solo $(14,1 \%)$ e mão-de-obra $(11,1 \%)$. Os maiores tempos consumidos foram durante a capina do povoamento (27,0\%), o plantio (22,0\%), os tratos culturais no viveiro (19,0\%) e a adubação $(13,0 \%)$.
\end{abstract}

Palavras-chave: Plantio de eucalipto, custo, rendimento.

\section{OPERATIONAL COSTS AND RETURNS IN EUCALYPT PLANTATION IN THE CERRADO REGION}

\begin{abstract}
The research in question was executed in an area dedicated to the stablishment of eucalipt forest population in the University of Brasilia's Agua Limpa Farm, with the aim of evaluating the production costs and time in the stages of seedling production, soil preparation, plantation and cultural treatments. All production costs of the various stages were analysed. Time was measured with the use of the individual time method. According to the results, the average cost for the establishment of one hectare of eucalypt was $R \$ 703,02$. The highest costs were obtained in the acquisition of trays and tubes (28,3\%), ant extermination $(16,7 \%)$, soil preparation $(14,0 \%)$ and labor $(11,0 \%)$. The highest consuming time was verified during weeding (27,0\%), plantation (22,0\%), cultivation at nursery $(19,0 \%)$ and fertilization $(13,0 \%)$.
\end{abstract}

Key words: Eucalypt plantation, cost, income.

\section{INTRODUÇÃO}

Os plantios florestais em áreas de cerrado são muito importantes no suprimento da demanda de madeira para os mais diversos fins, como lenha, carvão, postes, escoramentos, serraria e fabricação de papel. Uma das grandes funções atuais dos plantios, segundo Lima (1997), consiste em diminuir a pressão e a demanda por espécies nativas, muitas vezes com elevado risco de extinção. Segundo Sant' Anna e Mello (2000), para um planejamento adequado dos insumos, máquinas, ferramentas e mão-de-obra necessária, há necessidade

\footnotetext{
${ }^{1}$ Recebido para publicação em 27.3.2001 e aceito para publicação em 08.6.2004

${ }^{2}$ Departamento de Engenharia Florestal da Universidade Federal de Viçosa - 36570-000 Viçosa, MG.

Trabalho financiado pelo CNPq. E-mail: <krsilva@alunos.ufv.br>

${ }^{3}$ Departamento de Engenharia Florestal da Universidade de Brasília. Cx. Postal 04357 - 70919-970 Brasília, DF. E-mail: <fiedler@unb.br>

${ }^{4}$ Engenheiro Florestal da Universidade de Brasília. E-mail: <venturoli@rudah.com.br>.

${ }^{5}$ Bolsista de Iniciação Científica da Universidade de Brasília. E-mail: <sanag966@zaz.com.br>.
} 
de se fazer uma análise dos rendimentos operacionais e dos custos das atividades. Além disso, essas informações são muito importantes para se ter idéia a respeito do capital a ser investido na implantação do povoamento e servir de auxílio na tomada de decisão com relação à aquisição ou aluguel de determinados equipamentos.

A importância dos estudos de tempos e movimentos se dá em vários aspectos, principalmente quando se relaciona às suas inúmeras aplicações. As informações relativas aos custos de todas as etapas de implantação de um projeto são extremamente necessárias para a viabilização de recursos para a execução de cada fase. Aliado a isso, os custos dos investimentos, juntamente com as receitas futuras, no final do projeto, fazem parte da mola-mestra das análises de viabilidade do investimento.

Existem muitos fatores que atuam como variáveis nessa avaliação, mas sua importância é verificada quando comparada com uma produção sem planejamento financeiro, em que se pode gastar mais e produzir menos. A avaliação é baseada no fluxo de caixa, ou seja, nos custos e nas receitas distribuídas ao longo da vida útil do empreendimento.

Com a expansão acelerada da atividade florestal no Brasil, a região do cerrado passou a ter maior destaque no processo de reflorestamento do país devido, principalmente, ao fato de as condições edafoclimáticas e fisiográficas da região serem favoráveis ao estabelecimento de plantios de eucalipto (OLIVEIRA et al., 1998).

Projetos que analisam custos e rendimentos em operações florestais na região do cerrado são muito escassos e se fazem necessários para o planejamento de futuras áreas a serem implantadas. Assim, fornecem subsídios para as estimativas dos custos de produção, preços de fatores e produtos, demandas, possibilidades de substitutos, possíveis inovações técnicas, necessidade de mão-de-obra, máquinas, equipamentos, adubos e defensivos para serem usados como parâmetro na racionalização da produção florestal e na análise de viabilidades técnica e econômica em empresas e pequenas e médias propriedades (REZENDE e FONSECA, 1986).

O sucesso de um projeto depende da sua prévia avaliação, que resulta em racionalização das ativida- des para maximizar a produtividade e minimizar os custos de produção. Porém, a necessidade de avaliar um projeto que engloba várias etapas de execução, como produção e transporte de mudas, preparo do solo, combate à formiga, plantio e replantio, é de extrema importância para o profissional ligado à área florestal (REZENDE e SILVA, 1997).

Ao considerar os custos e rendimentos operacionais em plantios florestais, esta pesquisa objetivou avaliar os custos de produção e tempos gastos nas etapas de produção de mudas, preparo do solo, plantio e tratos culturais durante a implantação de um povoamento de eucalipto em área de cerrado.

\section{MATERIAL E MÉTODOS}

A pesquisa foi desenvolvida em uma área de reforma de Eucalyptus grandis W. Hill ex Maiden na Fazenda Água Limpa, localizada no núcleo rural Vargem Bonita (1556’14” S e 4746’08” W), em Brasília, DF. A altitude é de aproximadamente $1.100 \mathrm{~m}$. O clima é do tipo Aw, segundo a classificação de Köppen, e a precipitação média anual gira em torno de 1.600 mm.

A coleta de dados teve início em agosto de 1999 e término em março de 2000, acompanhando as atividades referentes à implantação do povoamento. Foram avaliados os custos e rendimentos operacionais de todas as etapas de produção, desde a semeadura até o plantio definitivo no campo com os respectivos tratos culturais.

A análise dos custos foi feita através do fluxo de caixa. Foi realizada uma pesquisa de preços acessíveis e qualidade satisfatória, com a ressalva de que, no final, optou-se pelas empresas que ofereceram os menores preços na aquisição do material necessário à execução do projeto. Foram avaliados também os custos diretos e indiretos da mão-de-obra utilizada.

Os tempos foram cronometrados por ciclo de trabalho, coletados e analisados pelo método de tempos individuais, em que, após cada medição, o cronômetro era zerado. Utilizaram-se um cronômetro digital da marca Tenlon e um cronômetro acoplado a um relógio de pulso, para obtenção dos dados. Os cronômetros têm graduação até a escala de milésimos, mas os dados foram considerados até a escala de segundos, em razão da facilidade de registro dos dados. O estudo de tempo permitiu a estimativa do tempo gasto por 
fase do ciclo e do tempo total gasto na operação.

Os dados foram processados com o auxílio de calculadora científica e planilha eletrônica desenvolvida no software Excel 7.0, da Microsoft.

O número mínimo de repetições utilizadas em cada fase deste estudo foi determinado a partir de uma amostragem-piloto analisada com o uso da seguinte fórmula, proposta por Conaw (1977):

$$
\mathrm{n} \geq\left(\mathrm{t}^{2} * \mathrm{~s}^{2}\right) / \mathrm{e}^{2}
$$

em que:

n = número de repetições necessárias;

$\mathrm{t}=$ coeficiente tabelado a $90 \%$ de probabilidade (distribuição de Student);

s = desvio-padrão de amostra; e

$\mathrm{e}=$ erro admissível $=10 \%$.

De acordo com os resultados, realizou-se a seguinte amostragem:

$\begin{array}{llcc} & \text { N } & \text { S } & \text { n } \\ \text { - Produção de mudas } & 80 & 0,22 & 13,51 \\ \text { - Capina } & 50 & 0,39 & 43,13 \\ \text { - Plantio } & 15 & 0,22 & 14,87 \\ \text { - Tratos culturais } & 32 & 0,33 & 31,37 \\ \text { - Adubação } & 35 & 0,18 & 9,33 \\ \text { - Preparo do solo } & 30 & 0,25 & 18,01\end{array}$

com Grade Bedding

sendo:

$\mathrm{N}=$ população amostrada;

n = população mínima estimada usando a fórmula; e

$\mathrm{S}=$ desvio-padrão da amostra.

Foram preparadas 207 bandejas com substrato composto por 33,3\% de plantmax, 33,3\% de vermiculita e 33,3\% de terra de subsolo. Cada bandeja tinha capacidade para 176 tubetes. Efetivamente, utilizaramse 35.168 tubetes do total de 36.432.

A jornada de trabalho era de oito horas diárias. A análise envolveu as atividades de semeadura, desbaste, raleio, adubação no viveiro, combate às formigas, preparo do solo, adubação, expedição e transporte das mudas para o campo, plantio, replantio e capina.

\section{RESULTADOS E DISCUSSÃO}

As sementes de Eucalyptus grandis foram semeadas em 35.168 tubetes, sendo o índice de germinação de 68\%, ou seja, 23.800 tubetes, o que é um índice baixo, considerando-se a qualidade das sementes.

Após todas as seleções, foram plantadas no campo 14.000 mudas (58,3\% do total semeado), em espaçamento de 3 × 3 m, totalizando um talhão de 12,6 ha. Outras 4.000 mudas (16,8\%) foram utilizadas na operação de replantio, devido a mortes por ataques de formigas, abundantes no local, e por ocorrência de veranicos, com a ressalva de que as principais perdas ocorreram em razão dos veranicos, já que o combate às formigas foi eficiente.

O custo inicial do preparo do viveiro com a construção das bancadas, aquisição dos tubetes, substrato, irrigação, adubação, combate a formigas e ferramentas utilizadas é apresentado no Quadro 1.

Quadro 1 - Custos do material adquirido para construção das bancadas no viveiro, para a realização do combate às formigas e capina

Table 1 - Cost of material acquired to build mursery counters for ant disinfestation and weeding

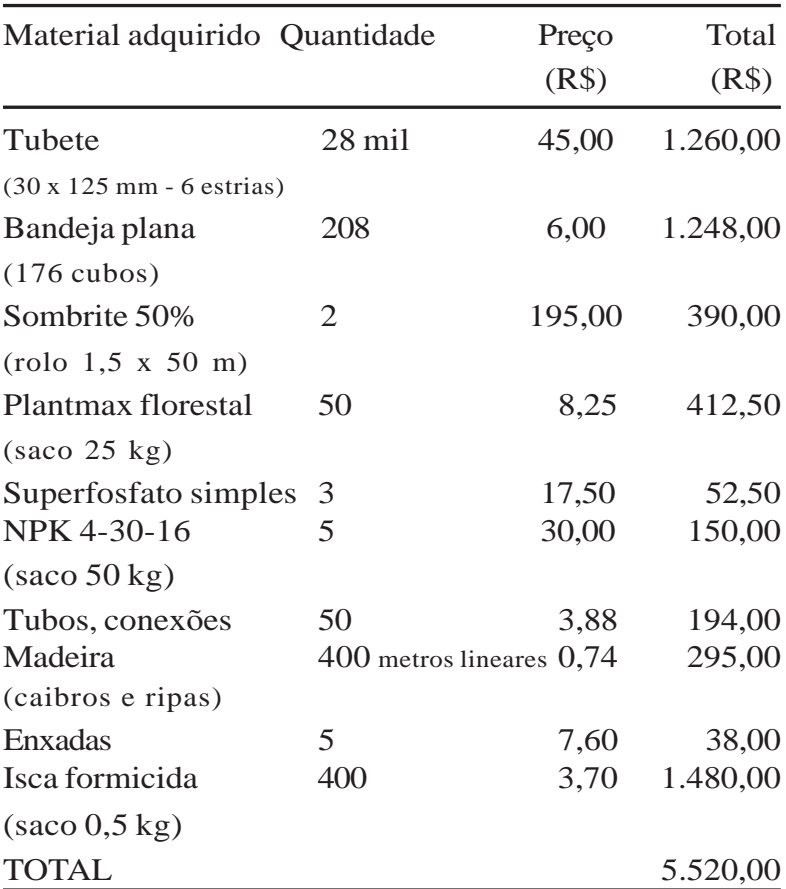


O maior custo na fase de estruturação do viveiro foi com a aquisição de material de maior durabilidade, como os tubetes e as bandejas.

O custo total da implantação do povoamento nos 12,6 ha, incluindo os custos sociais referentes à mãode-obra, chegou a R \$ 8.860,32, sendo o custo médio por hectare de R\$703,02. Desse total calculado, os custos com as bandejas e os tubetes integraram $28,3 \%$; o combate às formigas com iscas formicidas, $16,7 \%$; a adubação das mudas no campo consumiu $14,2 \%$ do custo total; o preparo do solo com a grade Bedding integrou $14,1 \%$; os custos de mão-de-obra foram de $11,1 \%$; os custos com a compra de material para a construção das bancadas no viveiro foram de 9,9\%, enquanto a etapa de produção das mudas integrou $5,3 \%$ e a capina, $0,4 \%$ do total. Tais resultados são mais bem visualizados pela análise da Figura 1.

Os resultados relativos aos tempos consumidos nas etapas são mostrados no Quadro 2.

As etapas de colocação dos tubetes na bandeja, enchimento dos tubetes com substrato e a semeadura foram realizadas por um único trabalhador, totalizando 35.168 tubetes preparados, em 5,1 dias, consumindo um tempo total médio de 39h 22' 52'”. Esse rendimento equivale ao dispêndio de $1 \mathrm{~h}$ 13' 7' por hectare de área plantada.

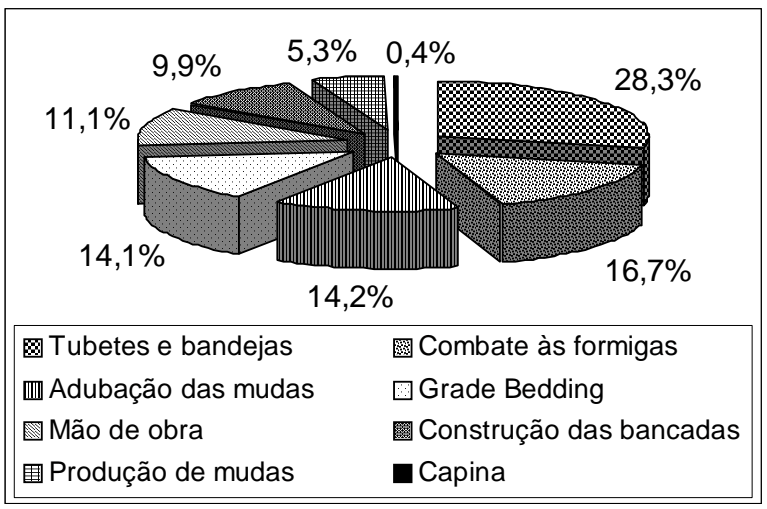

Figura 1 - Percentuais de custos das etapas de implantação de um povoamento florestal na região do cerrado.

Figure 1 - Percent cost of the forest implantion in cerrado region.
Quadro 2 - Tempos consumidos nas atividades desenvolvidas em $\mathrm{H} / \mathrm{H} / \mathrm{ha}$ ou $\mathrm{H} / \mathrm{M} /$ ha (hora-homem por hectare ou hora-máquina por hectare)

Table 2 - Estimates of the times of the project in $\mathrm{H} / \mathrm{H} / \mathrm{ha}$ or $\mathrm{H} / \mathrm{M} / \mathrm{ha}$

\begin{tabular}{|c|c|c|}
\hline Atividades & $\begin{array}{l}\text { Tempo médio } \\
\text { total (dias) }\end{array}$ & $\mathrm{H} / \mathrm{H} / \mathrm{ha}$ \\
\hline Produção de mudas & 5,1 & 1h 13' 7' \\
\hline Tratos culturais no viveiro & 10,5 & 3h 48' 18', \\
\hline Grade Bedding * & 5,5 & 3h 38' 43'” \\
\hline Adubação & 7,6 & 4h 50' 3'” \\
\hline Plantio & 12,4 & 7h 52' 39'” \\
\hline Capina & 15,4 & 9h 47' 32'” \\
\hline Total & 56,5 & 31h 10' 22'” \\
\hline
\end{tabular}

*Tempo em hora-máquina por hectare.

Como germinaram 23.800 sementes, os tratos culturais aplicados a essas mudas (desbaste e raleio), realizados por uma pessoa, foram completados, em média, em 10,5 dias ou 83h 41' 7'. Já o desbaste, que é demorado por ser feito com cuidado para não danificar a(s) muda(s) que permanecerá(ão) no tubete, representou cerca de $87 \%$ do tempo gasto nos tratos culturais. Um único trabalhador levava em torno de 3h 48' 18'" para desbastar e fazer o raleio do total de mudas suficientes para o plantio de 1 ha.

Na limpeza do terreno com a grade Bedding foi gasto um tempo de 45h 55' 51'' (5,7 dias). Nessa etapa foram necessárias pelo menos três passadas da grade para deixar a área bem limpa. O tempo calculado por hectare foi de 3h 38' 43'”.

A adubação foi realizada em 7,6 dias e o tempo médio estimado por hectare, de 4h 50' 3'”.

Verificou-se uma mortalidade de $16,8 \%$ das mudas no campo, sendo as principais causas os ataques de formigas e devido a um veranico ocorrido no mês de janeiro, logo após o plantio das primeiras mudas e um no início de fevereiro. Para isso foi realizado o replantio de 4.000 mudas. O tempo gasto nessa etapa foi muito variável, pois era preciso averiguar a situação de todas as mudas. Essa é uma etapa realizada no mínimo um mês após o plantio, tempo necessário para que a muda se estabeleça.

Os tempos gastos com controle de formigas não foram computados porque essa atividade era realiza- 
da aleatoriamente, podendo levar até o dia todo ou vários dias, dependendo da situação da área e da quantidade de formigueiros existentes.

Na etapa de plantio das mudas no campo foram gastos 12,4 dias de uma pessoa, aproximadamente 1 ha por dia ou 1 ha em 7h 52' 39'”.

Com relação à capina, estimou-se que um operador era capaz de capinar os 12,6 ha em 15,4 dias, com um tempo médio por hectare de 9h 47' 32'.

Para se implantar um povoamento homogêneo de eucalipto, o rendimento de um trabalhador foi de $31 \mathrm{~h}$ 10 ' 22' por hectare, dado que em 1 ha são necessárias 1.111 mudas (6,3 bandejas com capacidade para 176 tubetes), que são produzidas em $1 \mathrm{~h} 13^{\prime} 7^{\prime \prime}$. Os tratos culturais no viveiro ocuparam um tempo de $3 \mathrm{~h} 48^{\prime}$ ' 18', e a limpeza da área com a grade Bedding necessitou de 3h 38' 43'” já a etapa de adubação foi realizada em 4h 50' 3''. O plantio foi completado em 7h 52' 39' e a capina da área (limpeza), em 9h 47' 32'”.

Quando comparados os tempos gastos para a realização de cada fase do ciclo, de acordo com o total, observa-se, na Figura 2, que a atividade que exigiu mais tempo para ser completada foi a capina, que consumiu cerca de $27,0 \%$ do tempo total. Em seguida veio o plantio, realizado em $22,0 \%$ do tempo total. Os tratos culturais no viveiro (desbaste e raleio) foram realizados com 19,0\% do tempo. A etapa de adubação foi conduzida com $13,0 \%$ do tempo, e as demais fases de

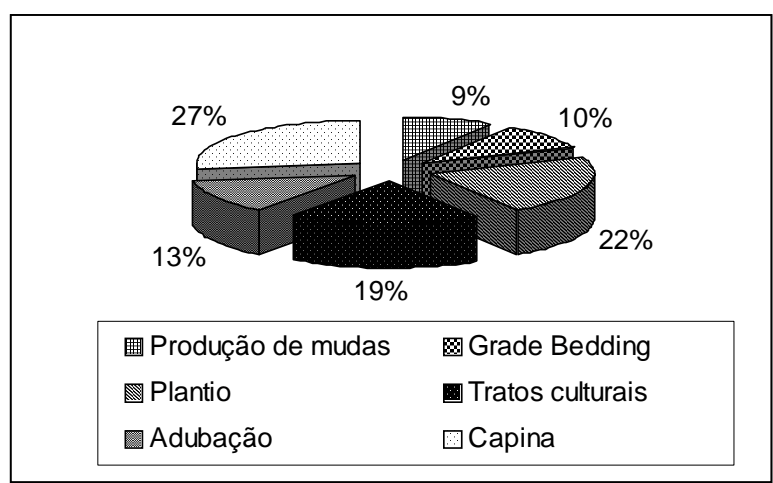

Figura 2 - Percentuais de tempos gastos nas etapas de implantação de um povoamento florestal na região do Cerrado.

Figure 2 -Percent cost of the forest implantion in cerrado region. produção de mudas e preparo do solo com a grade Bedding foram executadas quase no mesmo tempo, 9,0 e $10,0 \%$, respectivamente.

Esses resultados evidenciaram a importância deste estudo, pois com base nele se pode fazer o correto planejamento para verificar qual fase terá o maior dispêndio de tempo e custo, tanto de material, máquinas e equipamentos quanto da utilização da mãode-obra disponível, ou, mesmo, para realizar eventuais contratações.

\section{CONCLUSÕES}

Com base nos resultados obtidos, pode-se chegar as seguintes conclusões:

- O custo total para a implantação do talhão de 12,6 ha foi de $\mathrm{R} \$ 8.860,32$, correspondendo a um custo médio de R\$ 703, 02 por hectare.

- Os maiores custos observados foram na aquisição das bandejas e tubetes (28,3\%), combate a formigas (16,7\%), preparo do solo (14,0\%) e mão-de-obra (11,0\%).

- Os maiores tempos consumidos foram durante a capina do povoamento $(27,0 \%)$, plantio $(22,0 \%)$, tratos culturais no viveiro (19,0\%) e adubação (13,0\%). A redução dos tempos e custos, nas atividades de capina, pode ser obtida através da mecanização da atividade.

- Os resultados obtidos com essas análises foram dentro do esperado, que ressalta ainda mais a essencialidade de análises de custos aliadas a estudos de rendimentos operacionais como forma de planejar a produção, visando à minimização dos custos e à maximização do rendimento das atividades, tornando, assim, o projeto viável tanto técnica quanto economicamente.

- As atividades de combate às formigas devem ser prioritariamente realizadas durante os picos populacionais, para um maior sucesso no seu controle.

\section{5 - REFERÊNCIAS BIBLIOGRÁFICAS}

CONAW, P. L. Estatística. São Paulo: Edgard Blucher, 1977. 264 p.

LIMA, D. G. Importância das florestas plantadas como forma de reduzir a pressão sobre as florestas nativas ainda existentes. Revista Bahia Agrícola, v. 1, n. 3, p. 45-48, 1997.



R. Árvore, Viçosa-MG, v.28, n.3, p. 361-366, 2004 
MELLO, FILHO, O. A.; SANT’ANNA, C. M. Estudo de tempos e movimentos na desbrota do eucalipto com motorroçadora. In: SIMPÓSIO BRASILEIRO SOBRE SEGURANÇA NO

TRABALHO FLORESTAL E AGRÍCOLA, 1., 2000. Anais... [S.1.]: ERGOFLOR, 2000. p. 182-186

OLIVEIRA, A. D. et al. Avaliação econômica da vegetação de cerrado. Revista Cerne, v. 4, n. 1, p.34-56, 1998.
REZENDE, G. C.; FONSECA, E. P. Implantação da cultura do eucalipto. In: Informe

Agropecuário, v. 12, n. 141, p. 2024, 2004, 1986.

REZENDE, J. L. P.; SILVA, M. L. Elaboração e avaliação de um projeto de produção de madeira de Pinus sp. na Região de Ubá. Viçosa, MG: SIF, 1997. 61 p.: il. (Documento SIF, 15). 